\title{
Secure laparoscopic cholecystectomy with surgical technique modification in abdominal situs inversus
}

\author{
Egemen Çiçek, @ Fatih Sümer, • Kutay Sağlam, @ Cüneyt Kayaalp \\ Department of General Surgery, İnönü University Faculty of Medicine, Malatya, Turkey
}

To the Editor,

Situs inversus can be described as a mirror image placement opposite to normal anatomic sites of intraabdominal and/or intrathoracic organs. This rare anomaly was first described by Fabricius. ${ }^{[1,2]}$ The presence of the situs inversus is a significant factor that increase the likelihood of the anatomic variations. ${ }^{[3]}$ Cholecystectomy is a very frequent procedure in daily surgical practice. In the literature, laparoscopic surgery was performed in these patients, often less frequently than open surgery. ${ }^{[4]}$ Situs inversus which inherited otosomal recessively, can be diagnosed preoperatively with the development of the radiological imaging technique. Diagnosed patients has the chance of the surgical modifications taht increases the success. Here, we present a patient who had a cholecystitis episode and diagnosed abdominal Situs inversus as a result of the evaluation. The operative preparation, duration of the operation and the results are analyzed in the light of the literature.

Case

Forty six year old female patient admitted with a history of cholecystitis. In the evaluation, body temperature: $36.5^{\circ} \mathrm{C}$, arterial pressure $120 / 70 \mathrm{mmHg}$, pulse $70 / \mathrm{min}$, respiratory rate $20 / \mathrm{min}$ was found. Labaratory findings was as follows; WBC 12.1x103 (4.3-10.3) cell $/ \mathrm{mm}^{3}$, hemoglobin: $12.2 \mathrm{~g} / \mathrm{dL}$ (13.6-17.2), albumin: $3 \mathrm{~g} / \mathrm{dL}$ (3.4-4.8), aspartat amino transferase: $40 \mathrm{U} / \mathrm{L}$ (5-34), alanin amino transferase: $33 \mathrm{U} / \mathrm{L}(<55)$, gama glutamil transferase: 18 U/L (9-64), alcaline phosphatase: $73 \mathrm{U} / \mathrm{L}$ (40-150) total bilirubin: $0.46 \mathrm{mg} / \mathrm{dL}(0.2-1.2)$ direct bilirubin: $0.18 \mathrm{mg} /$ $\mathrm{dL}(<0.5)$. The abdominal ultrasonography of the patient revealed that the liver was located in the left upper quadrant and the intraabdominal organs was inversely in the form of a mirror image. Recurrent cholesistitis with numerous gall stones and normal biliary tract was reported. Cholecystectomy was planned. Additional pathology was not determined.

\section{Operative Tecnique}

The patient who had no previous operation with ASA 1 Laparoscopic cholecystectomy planned. The monitor positioned to the left side of the patient. Pneumoperitoneum was formed by veres needle and $\mathrm{CO}_{2}$ insufflation after incision made beneath the umbilicus. The first $10 \mathrm{~mm}$ trocar inserted at the same position and the other $10 \mathrm{~mm}$ trocar inserted under the xiphoid. After exploration of the abdominal organs, a $5 \mathrm{~mm}$ trocar was placed at the mid claviclar line and the other $5 \mathrm{~mm}$ trokar placed at the front axillary line. The patient was discharged on the first day after the operation with a duration of operation of 30 minutes. The pathologic evaluation was reported as chronic cholecystitis due to a large number of stones, the largest of which was $0.8 \mathrm{~cm}$ and the smallest is $0.4 \mathrm{~cm}$. The duration of follow up of the patient who has no complication is 4 months. 
Situs inversus may only be intraabdominal. Laparoscopic cholecystectomy and other surgical procedures in the patient group with anomalies can be successfully performed thanks to detailed preoperative evaluation and modification of routine techniques. Sarigoz et al. ${ }^{[5]}$ have emphasized that left-hand dominant surgeons make the dissection easier than right-hand dominant surgeons in their study. ${ }^{[5]}$ Our case was made by the right hand dominant surgeon and there was no difficulty in the dissection. Biliary duct injuries are rarely reported on the situs inversus. ${ }^{[6]}$ More careful implementation of safe cholecystectomy guidelines in laparoscopic cholecystectomy is important to reduce morbidity since it increases the likelihood of anatomic variation presence by the situs inversus.

\section{References}

1. Yaghan RJ, Gharaibeh KI, Hammori S. Feasibility of laparo- scopic cholecystectomy in situs inversus. J Laparoendosc Adv Surg Tech A 2001;11:233-7. [CrossRef]

2. Iskandar ME, Radzio A, Krikhely M, Leitman IM. Laparoscopic cholecystectomy for a left-sided gallbladder. World J Gastroenterol 2013 21;19:5925-8. [CrossRef]

3. Kulesza RJ Jr, Kalmey JK, Dudas B, Buck WR. Vascular anomalies in a case of situs inversus. Folia Morphol (Warsz) 2007;66:69-73.

4. Machado NO, Chopra P. Laparoscopic cholecystectomy in a patient with situs inversus totalis: feasibility and technical difficulties. JSLS 2006;10:386-91.

5. Sarigoz T, Ertan T, Topuz O, Sevim Y. Laparoscopic cholecystectomy in patients with situs inversus totalis: case report and review of reported surgical techniques. Laparosc Endosc Surg Sci 2017;24:104-6. [CrossRef]

6. Usta $S$, Karabulut K. Bile duct injury following laparoscopic cholecystectomy in a patient with situs inversus. Laparosc Endosc Surg Sci 2017;24:141-2. 